\title{
Mammalian cell transfection: the present and the future
}

\author{
Tae Kyung Kim • James H. Eberwine
}

Received: 9 February 2010 /Revised: 28 April 2010 / Accepted: 3 May 2010 / Published online: 13 June 2010

(C) The Author(s) 2010. This article is published with open access at Springerlink.com

\begin{abstract}
Transfection is a powerful analytical tool enabling study of the function of genes and gene products in cells. The transfection methods are broadly classified into three groups; biological, chemical, and physical. These methods have advanced to make it possible to deliver nucleic acids to specific subcellular regions of cells by use of a precisely controlled laser-microcope system. The combination of point-directed transfection and mRNA transfection is a new way of studying the function of genes and gene products. However, each method has its own advantages and disadvantages so the optimum method depends on experimental design and objective.
\end{abstract}

Keywords Transfection $\cdot$ Nucleic acid $\cdot$ Gene $\cdot$ Single cell

\section{Introduction}

Transfection is a procedure that introduces foreign nucleic acids into cells to produce genetically modified cells. Transfection is a powerful analytical tool for study of gene function and regulation and protein function. The introduced genetic materials (DNAs and RNAs) exist in cells either stably or transiently depending on the nature of the

T. K. Kim · J. H. Eberwine

Department of Pharmacology,

University of Pennsylvania Medical School—Pharmacology,

36th and Hamilton Walk,

Philadelphia, PA 19104, USA

J. H. Eberwine $(\square)$

Penn Genome Frontiers Institute,

University of Pennsylvania Medical School-Pharmacology,

36th and Hamilton Walk,

Philadelphia, PA 19104, USA

e-mail: eberwine@upenn.edu genetic materials [1]. For stable transfection, introduced genetic materials that usually have a marker gene for selection (transgenes) are integrated into the host genome and sustain transgene expression even after host cells replicate (Fig. 1a) [2]. In contrast with stably transfected genes, transiently transfected genes are only expressed for a limited period of time and are not integrated into the genome (Fig. 1b) [1]. Transiently transfected genetic materials can be lost by environmental factors and cell division, so the choice of stable or transient transfection depends on the objective of the experiment. The main purpose of transfection is to study the function of genes or gene products, by enhancing or inhibiting specific gene expression in cells, and to produce recombinant proteins in mammalian cells [3]. Examples are: gene therapy delivering a gene of interest into cells to cure a disease or improve symptoms; induced pluripotent stem cell (iPS cell) generation by transfecting three or four transcription factors; small interference RNA (siRNA) knock-down procedures; and production of human tissue plasminogen activator in immortalized Chinese hamster ovary $(\mathrm{CHO})$ cells for therapeutic purpose [3-6].

\section{Methodological diversity}

Many transfection methods have been developed (Table 1). Each method uses different approaches that must be considered depending on cell type and purpose. The ideal method should have high transfection efficiency, low cell toxicity, minimal effects on normal physiology, and be easy to use and reproducible.

For this discussion, the methods are broadly classified into biologically, chemically, and physically mediated methods. 
Fig. 1 Schematic diagrams of two different transfections. (a) Stable transfection. Foreign DNA (red wave) is delivered to nucleus by passage through the cell and nuclear membranes. Foreign DNA is integrated into the host genome (black wave) and expressed sustainably. (b). Transient transfection. Foreign DNA is delivered into the nucleus but is not integrated into the genome. Foreign mRNA (blue wave) is also delivered into the cytosol, where it is translated. Hexagons are expressed proteins from transfected nucleic acids. Black arrows indicate delivery of foreign nucleic acids

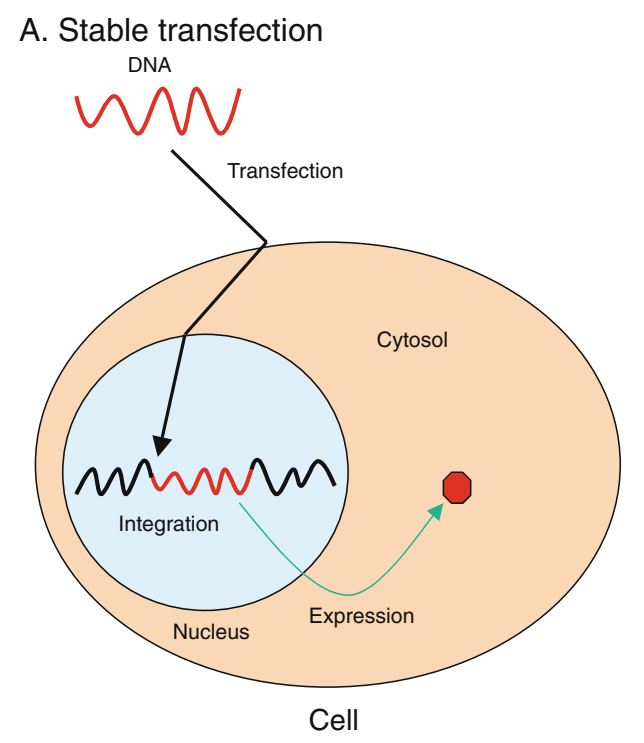

B. Transient transfection

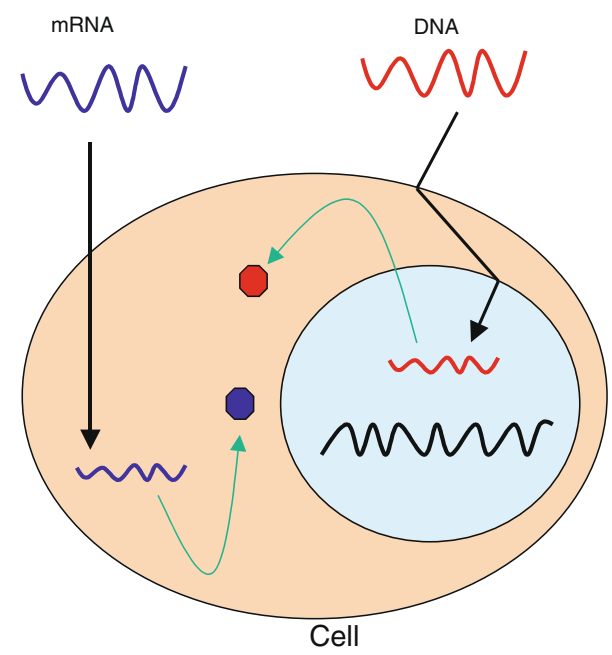

\section{Biological methods}

The most commonly used method in clinical research is virus-mediated transfection, also known as transduction [4]. Virus-mediated transfection is highly efficient and it is easy to achieve sustainable transgene expression in vivo owing to the viral nature of integration into the host genome. For example, retrovirus murine leukemia virus (MLV) has been used as a viral vector to establish sustainable transgene expression in humans [7, 8]. MLV integrates its DNA into the host genome and the integrated DNA is expressed in the host. The integrated MLV DNA replicates as the host

Table 1 Conventional transfection methods

\begin{tabular}{|c|c|c|c|c|c|}
\hline Class & Methods & Advantages & Disadvantages & Examples & Refs. \\
\hline Biological & - Virus-mediated & $\begin{array}{l}\text { - High-efficiency } \\
\text { - Easy to use } \\
\text { - Effective on dissociated } \\
\text { cells, slices, and in vivo }\end{array}$ & $\begin{array}{l}\text { - Potential hazard to } \\
\text { laboratory personnel } \\
\text { - Insertional mutagenesis } \\
\text { - Immunogenicity } \\
\text { - DNA package size limit }\end{array}$ & $\begin{array}{l}\text { Herpes simplex virus, Adeno } \\
\text { virus, Adeno-associated virus, } \\
\text { Vaccinia virus, Sindbis virus }\end{array}$ & {$[4,7-9]$} \\
\hline Chemical & $\begin{array}{l}\text { - Cationic polymer } \\
\text { - Calcium phosphate }\end{array}$ & $\begin{array}{l}\text { - Easy to use } \\
\text { - Effective on dissociated } \\
\text { cells and slices } \\
\text { - Plenty of commercially } \\
\text { available products } \\
\text { - No package size limit }\end{array}$ & $\begin{array}{l}\text { - Chemical toxicity to some } \\
\text { cell types } \\
\text { - Variable transfection } \\
\text { efficiency by cell type } \\
\text { or condition } \\
\text { - Hard to target specific cells }\end{array}$ & $\begin{array}{l}\text { DEAE-dextran, polyethyleneimine, } \\
\text { dendrimer, polybrene, calcium } \\
\text { phosphate, lipofectin, DOTAP, } \\
\text { lipofectamine, CTAB/DOPE, } \\
\text { DOTMA }\end{array}$ & {$[10-12]$} \\
\hline Physical & $\begin{array}{l}\text { - Direct injection } \\
\text { - Biolistic particle } \\
\text { delivery } \\
\text { - Electroporation } \\
\text { - Laser-irradiation } \\
\text { - Sonoporation } \\
\text { - Magnetic } \\
\text { nanoparticle }\end{array}$ & $\begin{array}{l}\text { - Simple principle and } \\
\text { straightforward } \\
\text { - Physical relocation of } \\
\text { nucleic acids into cell } \\
\text { - No need for vector } \\
\text { - Less dependent on cell type } \\
\text { and condition } \\
\text { - Single-cell transfection }\end{array}$ & $\begin{array}{l}\text { - Needs special instruments } \\
\text { - Vulnerable nucleic acids } \\
\text { - Demands experimenter skill, } \\
\text { laborious procedure }\end{array}$ & $\begin{array}{l}\text { Micro-needle, AFM tip, Gene } \\
\text { Gun, Amaxa Nucleofector, } \\
\text { phototransfection, Magnetofection }\end{array}$ & [13-25] \\
\hline
\end{tabular}


genome does. Consequently it segregates into daughter cells, which enables sustainable transgene expression.

The major drawbacks of virus-mediated transfection are immunogenicity and cytotoxicity. Introduction of a viral vector may cause an inflammatory reaction and an insertional mutation, because viral vectors integrate into the host genome randomly, which may disrupt tumor suppressor genes, activate oncogenes, or interrupt essential genes [9]. Another disadvantage of this method is that a virus package has limited space for a foreign gene to keep infectivity. For these reasons, much effort has been made to develop non-viral transfection methods even though virusmediated transfection is highly effective and easy to use.

\section{Chemical methods}

Chemical transfection methods are the most widely used methods in contemporary research and were the first to be used to introduce foreign genes into mammalian cells [10]. Chemical methods commonly use cationic polymer (one of the oldest chemicals used), calcium phosphate, cationic lipid (the most popular method), and cationic amino acid [10-12]. The underlying principle of chemical methods is similar. Positively charged chemicals make nucleic acid/ chemical complexes with negatively charged nucleic acids. These positively charged nucleic acid/chemical complexes are attracted to the negatively charged cell membrane. The exact mechanism of how nucleic acid/chemical complexes pass through the cell membrane is unknown but it is believed that endocytosis and phagocytosis are involved in the process. Transfected DNA must be delivered to the nucleus to be expressed and again the translocation mechanism to the nucleus is not known.

The transfection efficiency of chemical methods is largely dependent on factors such as nucleic acid/chemical ratio, solution $\mathrm{pH}$, and cell membrane conditions, so the process results in low transfection efficiency, especially in vivo, compared with virus-mediated methods. However, these methods have merits of relatively low cytotoxicity, no mutagenesis, no extra-carrying DNA, and no size limitation on the packaged nucleic acid. Chemical transfection efficiency also varies depending on cell type.

\section{Physical methods}

The physical transfection methods are the most recent methods and use diverse physical tools to deliver nucleic acids. The methods include direct micro injection, biolistic particle delivery, electroporation, and laser-based transfection [13]. In brief, the micro injection method directly injects nucleic acid into the cytoplasm or nucleus [14, 15]. This method delivers nucleic acids into cells but demands skill, often causes cell death, and is very labor-intensive. Biolistic particle delivery employs gold particles that conjugate with nucleic acids [16, 17]. The nucleic acid/particle conjugates are then shot into recipient cells at a high velocity ("gene gun"). This method is straightforward and reliable but it requires expensive instruments and causes physical damage to samples. Electroporation is the most widely used physical method. The exact mechanism is unknown but it is supposed that a short electrical pulse disturbs cell membranes and makes holes in the membrane through which nucleic acids can pass [18]. Because electroporation is easy and rapid, it is able to transfect a large number of cells in a short time once optimum electroporation conditions are determined. Laser-mediated transfection (also known as optoporation or phototransfection) uses a pulse laser to irradiate a cell membrane to form a transient pore [19-22]. When the laser induces a pore in the membrane, nucleic acids in the medium are transferred into the cell because of the osmotic difference between the medium and the cytosol. The laser method enables one to observe the transfecting cell and to make pores at any location on the cell. This method can be applied to very small cells, because it uses a laser, but it requires an expensive laser-microscope system. In addition to those mentioned above, there are other physical methods using ultrasound (sonoporation) and magnetic field (magnetofection) [23-25].

\section{Transfection of RNAs}

Transfecting mRNA has several merits over DNA transfection [26]. The merits include no risk of integration into the host genome, cell cycle-independent transfection efficiency, no need for immune inducible vectors, and adjustable and rapid expression. Using mRNA transfection, one can introduce any number of mRNAs into a cell, thereby overcoming overexpression of the genes. These advantages mostly originate from the fact that mRNA does not need to be located in a nucleus to be expressed. Transfected DNA must carry a host cell or tissue-specific promoter to be transcribed to mRNA and the expression level is determined by strength of the promoter. In contrast with DNA transfection, one can adjust expression levels by changing the amount of mRNA transfected and the frequency of transfection in mRNA transfection. Other strong advantages of mRNA transfection are:

1. transfected mRNAs can be expressed within minutes after transfection because it skips translocation to the nucleus and transcription process; and

2. transcriptome (population of mRNAs) can be used for transfection, which is practically difficult in DNA transfection (Fig. 2) [20, 27, 28]. 
Fig. 2 Micrographs of the rat hippocampal neuron lipotransfected with in-vitro-transcribed rat Gria4-GFP mRNA. (a) DIC image. (b) Fluorescence image before transfection. $\mathbf{c}, \mathbf{d}, \mathbf{e}$, and f. Fluorescence images 2, 4, 6, and $8 \mathrm{~h}$, respectively, after time-dependant increases in fluorescence transfection. Note the
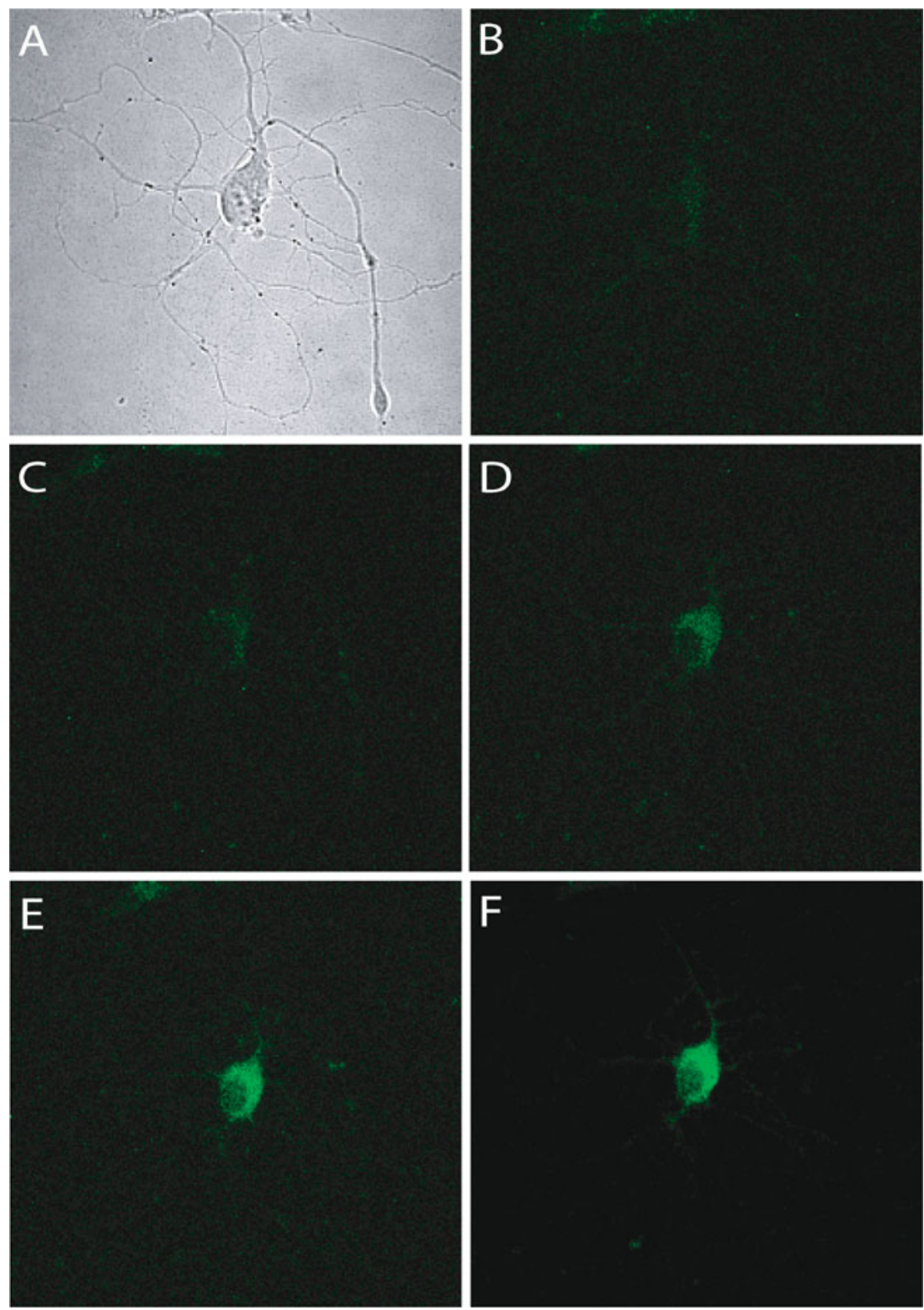

For these reasons, transfecting RNA is attracting interest for therapeutic purposes [29]. However, we have to acknowledge that matured mRNA consists of five significant structures (the cap, 5' untranslated region (5'UTR), open reading frame (ORF), 3' untranslated region (3'UTR), and poly-A tail) and undergoes nucleoside modifications, which are important to the translation of the mRNA [30, 31]. Therefore the plasmid used for in-vitro transcription must be designed with consideration of all factors affecting stability and translational efficiency. Handling mRNA demands more caution but mRNA transfection encourages alternation with DNA transfection for many applications.

RNA interference (RNAi) is a powerful tool to knockdown specific genes and to observe consequent changes of phenotypes [6, 32]. Introduced small inhibitory RNAs (siRNA) form RNA-induced silencing complex (RISC) in

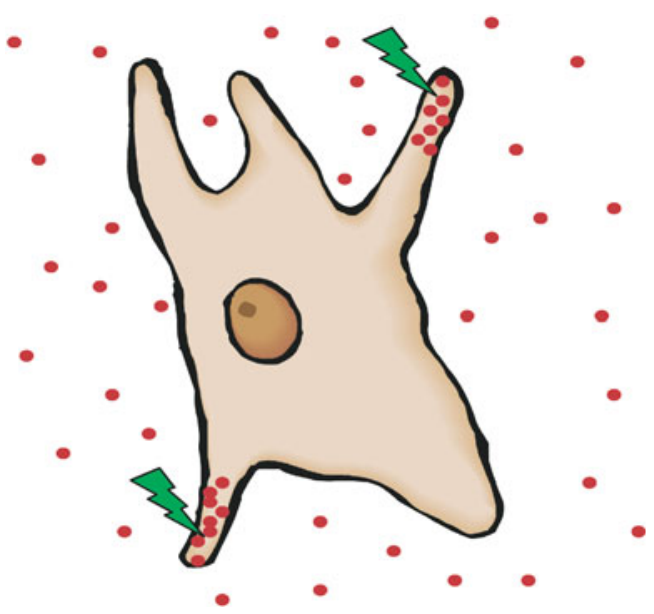

Fig. 3 An illustration of phototransfection. Laser beams (green flashes) create holes at specific regions of single cell (subcellular locations) and nucleic acids (red dots) are delivered into the local areas 
the cell and the RISC inhibits the expression of target gene expression. The most common methods used to deliver siRNA are lipid/polymer-mediated delivery and virusmediated delivery. Despite the wide use of siRNA, large efforts are still being made to develop more effective, safe, and reliable methods to deliver siRNAs into cells, because of the great potential of RNAi in clinical use to treat diseases [33]. Both relatively new transfection methods, mRNA and siRNA transfection, lead to new ways to execute cell research with their own distinctive advantages.

\section{Single-cell transfection}

Each cell has distinct gene-expression patterns even when sharing morphological similarities. Because the functions of a cell are determined by its location and time, single-cell resolution of gene expression is important to elucidate gene function. To achieve single-cell resolution of gene function, reliable single-cell transfection methods are needed. Some physical transfection methods have been applied to singlecell transfection with good results. Examples are:

1. micro-injections using a very small glass needle, nanoneedle, femtosyringe. and atomic-force microscopy (AFM) tips [34-37];

2. electroporation using a micropipette filled with nucleic acids and an electric field [38]; and

3. phototransfection using a multi-photon laser [20].

All methods are performed under a microscope so that transfected cells can be trailed in real time. Micro-injection is straightforward and efficient but all the types of injectors actually perforate cell membranes resulting in physical damage to the cells. Single-cell electroporation efficiently delivers nucleic acids into single cells and can easily be applied in vivo. Single-cell electroporation of enhanced green fluorescence protein (EGFP) plasmid has shown the morphology and growth characteristics of a single neuron in vivo [38]. Phototransfection is the most accurate means of delivering nucleic acids (Fig. 3). Because the numbers and sizes of holes on the cell membrane can be adjusted, this method is the most suitable way of delivering population mRNAs. The additional advantage of phototransfection is that we can dictate subcellular location through which nucleic acids pass (e.g. axon or dendrite on neuron), which is not possible by electroporation. Introducing nucleic acids into a subcellular location is important for study of single polarized cells in which different cellular domains perform distinct activities. Neurons, especially, have soma, dendrites, and axons, each with a different function and localized gene expression. For example, transfection of E26-like protein 1 (Elk-1) mRNA into dendrites of intact primary rat neurons induced cell death but introduction of Elk-1 mRNA in cell body did not cause cell death [20].
This experiment proved that localization of specific mRNA significantly altered the function of the mRNA, which was impossible to do using traditional transfection methods. The experiment could not be performed without a combination of mRNA transfection and subcellular locational transfection. Therefore, the combination of mRNA transfection and phototransfection is a powerful tool for study of gene function in single cells by virtue of point-directed delivery and immediate action of mRNA.

\section{Outlook}

Transfection methods are evolving rapidly. Even within a class, many new products and technologies are launched each year with improved efficiency and less cytotoxicity. From the virus-mediated method to laser-mediated method, each method has its own advantages and disadvantages so selection of the best method depends upon the experimenter's experimental objectives.

Future transfection technology should expand in two directions, being precise enough to transfect subcellular regions and up to whole-individual transfection. The ability to deliver foreign nucleic acids (especially mRNA) into subcellular locations (e.g. axon or dendrite) and organelles (e.g. mitochondria, golgi apparatus, or nucleus) will open an new era for genetic research because it will change how we think about and assess the function of genes in a cell. In addition to the overall gene expression profiles of a cell, the location of expressed gene products plays a crucial role in determining the function of a cell [20]. Meanwhile, safe and reliable transfection methods that can be applicable to humans are needed to establish clinical therapeutics.

In summary, transfection methodology has developed rapidly and diversely. Consequently we now have plenty of options to choose from, fitting well into our experimental or clinical needs. However, as cell research progresses, more advanced transfection technologies are still in demand.

Open Access This article is distributed under the terms of the Creative Commons Attribution Noncommercial License which permits any noncommercial use, distribution, and reproduction in any medium, provided the original author(s) and source are credited.

\section{References}

1. Recillas-Targa F (2006) Multiple strategies for gene transfer, expression, knockdown, and chromatin influence in mammalian cell lines and transgenic animals. Mol Biotechnol 34(3):337-354

2. Glover DJ, Lipps HJ, Jans DA (2005) Towards safe, non-viral therapeutic gene expression in humans. Nat Rev Genet 6(4):299 310

3. Wurm FM (2004) Production of recombinant protein therapeutics in cultivated mammalian cells. Nat Biotechnol 22(11):1393-1398 
4. Pfeifer A, Verma IM (2001) Gene therapy: promises and problems. Annu Rev Genomics Hum Genet 2:177-211

5. Takahashi K, Yamanaka S (2006) Induction of pluripotent stem cells from mouse embryonic and adult fibroblast cultures by defined factors. Cell 126(4):663-676

6. Hamilton AJ, Baulcombe DC (1999) A species of small antisense RNA in posttranscriptional gene silencing in plants. Science 286 (5441):950-952

7. Hacein-Bey-Abina S et al (2002) Sustained correction of X-linked severe combined immunodeficiency by ex vivo gene therapy. $\mathrm{N}$ Engl J Med 346(16):1185-1193

8. Roesler J et al (2002) Third-generation, self-inactivating gp91 (phox) lentivector corrects the oxidase defect in NOD/SCID mouse-repopulating peripheral blood-mobilized CD34+ cells from patients with X-linked chronic granulomatous disease. Blood 100 (13):4381-4390

9. Woods NB et al (2003) Lentiviral vector transduction of NOD/ SCID repopulating cells results in multiple vector integrations per transduced cell: risk of insertional mutagenesis. Blood 101 (4):1284-1289

10. Schenborn ET, Goiffon V (2000) DEAE-dextran transfection of mammalian cultured cells. Meth Mol Biol 130:147-153

11. Holmen SL et al (1995) Efficient lipid-mediated transfection of DNA into primary rat hepatocytes. In Vitro Cell Dev Biol Anim 31(5):347-351

12. Washbourne P, McAllister AK (2002) Techniques for gene transfer into neurons. Curr Opin Neurobiol 12(5):566-573

13. Mehier-Humbert S, Guy RH (2005) Physical methods for gene transfer: improving the kinetics of gene delivery into cells. Adv Drug Del Rev 57(5):733-753

14. Martinou I et al (1995) Viral proteins E1B19K and p35 protect sympathetic neurons from cell death induced by NGF deprivation. J Cell Biol 128(1-2):201-208

15. Ikeda SR et al (1995) Heterologous expression of metabotropic glutamate receptors in adult rat sympathetic neurons: subtypespecific coupling to ion channels. Neuron 14(5):1029-1038

16. Lo DC, McAllister AK, Katz LC (1994) Neuronal transfection in brain slices using particle-mediated gene transfer. Neuron 13 (6): 1263-1268

17. O'Brien JA, Lummis SC (2006) Biolistic transfection of neuronal cultures using a hand-held gene gun. Nat Protoc 1 (2):977-981

18. Inoue $T$, Krumlauf R (2001) An impulse to the brain-using in vivo electroporation. Nat Neurosci 4:1156-1158

19. Shirahata $Y$ et al (2001) New technique for gene transfection using laser irradiation. J Investig Med 49(2):184-190
20. Barrett LE et al (2006) Region-directed phototransfection reveals the functional significance of a dendritically synthesized transcription factor. Nat Meth 3(6):455-460

21. Yao CP et al (2008) Laser-based gene transfection and gene therapy. IEEE Trans Nanobioscience 7(2):111-119

22. Schneckenburger $\mathrm{H}$ et al (2002) Laser-assisted optoporation of single cells. J Biomed Opt 7(3):410-416

23. Kim HJ et al (1996) Ultrasound-mediated transfection of mammalian cells. Hum Gene Ther 7(11):1339-1346

24. Dobson J (2006) Gene therapy progress and prospects: magnetic nanoparticle-based gene delivery. Gene Ther 13(4):283-287

25. Scherer F et al (2002) Magnetofection: enhancing and targeting gene delivery by magnetic force in vitro and in vivo. Gene Ther 9 (2):102-109

26. Yamamoto A et al (2009) Current prospects for mRNA gene delivery. Eur J Pharm Biopharm 71(3):484-489

27. Job C, Eberwine J (2001) Identification of sites for exponential translation in living dendrites. Proc Natl Acad Sci USA 98 (23):13037-13042

28. Sul JY et al (2009) Transcriptome transfer produces a predictable cellular phenotype. Proc Natl Acad Sci USA 106(18):7624-7629

29. Sullenger BA, Gilboa E (2002) Emerging clinical applications of RNA. Nature 418(6894):252-258

30. Rozenski J, Crain PF, McCloskey JA (1999) The RNA Modification Database: 1999 update. Nucleic Acids Res 27(1):196-197

31. Elango $\mathrm{N}$ et al (2005) Optimized transfection of mRNA transcribed from a $\mathrm{d}(\mathrm{A} / \mathrm{T}) 100$ tail-containing vector. Biochem Biophys Res Commun 330(3):958-966

32. Brazas RM, Hagstrom JE (2005) Delivery of small interfering RNA to mammalian cells in culture by using cationic lipid/ polymer-based transfection reagents. Meth Enzymol 392:112-124

33. Castanotto D, Rossi JJ (2009) The promises and pitfalls of RNAinterference-based therapeutics. Nature 457(7228):426-433

34. Davis BR et al (2000) Micro-injection-mediated hematopoietic stem cell gene therapy. Curr Opin Mol Ther 2(4):412-419

35. Han S et al (2005) Gene expression using an ultrathin needle enabling accurate displacement and low invasiveness. Biochem Biophys Res Commun 332(3):633-639

36. Knoblauch $M$ et al (1999) A galinstan expansion femtosyringe for microinjection of eukaryotic organelles and prokaryotes. Nat Biotechnol 17(9):906-909

37. Cuerrier CM, Lebel R, Grandbois M (2007) Single cell transfection using plasmid decorated AFM probes. Biochem Biophys Res Commun 355(3):632-636

38. Haas K et al (2001) Single-cell electroporation for gene transfer in vivo. Neuron 29(3):583-591 